\title{
COMPUTATIONAL FLUID DYNAMICS SIMULATION FOR MINIMUM PIPE-VENTILATION SYSTEM INSIDE BROILER BUILDING IN WINTER SEASON
}

\author{
EHAB MOSTAFA* - IN-BOK LEE ${ }^{* *}$
}

\begin{abstract}
Increasing broiler performance and its productivity during winter season is the main purpose for all researchers. The ideal temperature for the best weight gain and feed efficiency varies depending on birds age from 33-21 ${ }^{\circ} \mathrm{C}$. Accordingly, the ventilation management has become one of the most important means of adapting and maintain the inside air temperature. The external air temperature in South Korea where the experiments were done is decreasing during winter season up to $-20{ }^{\circ} \mathrm{C}$. Under this condition from low air temperature, minimum ventilation must be provided. 3D-CFD model for broiler house with pipe ventilation system was designed to reach the required ventilation rate, air temperature, thermal uniformity and stability during winter season. To test this ventilation system under real conditions, computational fluid dynamic simulation was used to overcome the field experiments limitations. Field experiment aim to validate the conventional case was performed and the designed case was upgraded accordingly. The upgraded pipe ventilation system efficiency for reducing the Ammonia concentration in broiler zone was also examined. From the data analyzed, the upgraded case achieved suitable ventilation rate, air temperature distribution and Ammonia concentration reduction.
\end{abstract}

Keywords: Computational fluid dynamics; pipe-ventilation; air temperature distribution; broiler house

\footnotetext{
*Assist. Prof., Ag. Eng. Dept., Fac. of Agric., Cairo Univ.

** Associate Prof., Dept. of Rural Systems Engineering and Research Institute for Agriculture and Life Sciences, College of Agriculture and Life Sciences, Seoul National University, South Korea
} 


\section{NOMENCLATURE}

\begin{tabular}{|c|c|}
\hline $\mathrm{S}_{\mathrm{m}}$ & Mass source, $\mathrm{kg} \mathrm{m}^{-3}$ \\
\hline$\rho$ & Density, $\mathrm{kg} \mathrm{m}^{-3}$ \\
\hline $\mathrm{u}, \mathrm{v}, \mathrm{w}$ & Velocity, $\mathrm{m} \mathrm{s}^{-1}$ \\
\hline $\mathrm{P}$ & Constant pressure, $\mathrm{Pa}$ \\
\hline $\mathrm{F}$ & External force vector, $\mathrm{N} \mathrm{m}^{-3}$ \\
\hline $\mathrm{g}$ & Gravitational acceleration, $\mathrm{m} \mathrm{s}^{-2}$ \\
\hline $\mathrm{E}$ & Total energy, J \\
\hline $\mathrm{k}_{\mathrm{eff}}$ & Heat transmission coefficient \\
\hline $\mathrm{h}$ & Specific enthalpy, $\mathrm{J} \mathrm{kg}^{-1}$ \\
\hline $\mathrm{J}$ & Component of diffusion flux, $\mathrm{kg} \mathrm{m}^{-2} \mathrm{~s}^{-1}$ \\
\hline$\tau$ & Stress tensor, $\mathrm{Pa}$ \\
\hline $\mathrm{S}_{\mathrm{h}}$ & Total entropy, $\mathrm{J} \mathrm{K}^{-1}$ \\
\hline $\mathrm{K}$ & Turbulent kinetic energy, $\mathrm{m}^{2} \mathrm{~s}^{-2}$ \\
\hline$\mu_{\text {eff }}$ & Effective viscosity $\left(\mu=\mu_{t}\right), \mathrm{m}^{2} \mathrm{~s}$ \\
\hline$\mu$ & Viscosity, $\mathrm{m}^{2} \mathrm{~s}$ \\
\hline$\mu_{\mathrm{t}}$ & Turbulent viscosity, $\mathrm{m}^{2} \mathrm{~s}$ \\
\hline $\mathrm{G}_{\mathrm{k}}$ & $\begin{array}{l}\text { Generation of turbulent kinetic energy due to the mean } \\
\text { velocity gradients, } \mathrm{kgm}^{-1} \mathrm{~s}^{-2}\end{array}$ \\
\hline $\mathrm{G}_{\mathrm{b}}$ & Generation of kinetic energy due to the buoyancy, $\mathrm{kgm}^{-1} \mathrm{~s}^{-2}$ \\
\hline$\varepsilon$ & Turbulent dissipation rate, $\mathrm{m}^{2} \mathrm{~s}^{-3}$ \\
\hline $\mathrm{Y}_{\mathrm{M}}$ & $\begin{array}{l}\text { Contribution of the fluctuating dilatation in compressible } \\
\text { turbulence to the overall dissipation rate, } \mathrm{kg} \mathrm{m}^{-1} \mathrm{~s}^{-2}\end{array}$ \\
\hline$\alpha_{\mathrm{k}}$ & $\begin{array}{l}\text { Generation of kinetic energy due to the mean velocity } \\
\text { gradients, } \mathrm{kg} \mathrm{m}^{-1} \mathrm{~s}^{-2}\end{array}$ \\
\hline$\alpha_{\varepsilon}$ & Generation of kinetic energy due to buoyancy, $\mathrm{kg} \mathrm{m}^{-1} \mathrm{~s}^{-2}$ \\
\hline $\mathrm{C}_{1 \varepsilon}$ and $\mathrm{C}_{2 \varepsilon}$ & Constant of 1.42 and 1.68 \\
\hline $\mathrm{C}_{3 \varepsilon}$ & $\begin{array}{l}\tanh \left(\mathrm{u}_{1} / \mathrm{u}_{2}\right), \mathrm{u}_{1} \text { and } \mathrm{u}_{2} \text { are components of the flow } \\
\text { velocities parallel and perpendicular, respectively, to the } \\
\text { gravitational vector }\end{array}$ \\
\hline $\mathrm{R}$ & The gas-law constant, $8.31447 \times 10^{3} \mathrm{~J} \mathrm{~kg} \mathrm{~mol}^{-1} \mathrm{~K}^{-1}$ \\
\hline $\mathrm{C}_{\mu}$ & Experimental constant \\
\hline $\mathrm{Z}_{\mathrm{n}}$ & Vertical height from the ground, $\mathrm{m}$ \\
\hline$\delta$ & Thickness of the turbulent boundary layer, $\mathrm{m}$ \\
\hline THP & Total heat production, $\mathrm{W} \mathrm{m}^{-2}$ \\
\hline
\end{tabular}


Increasing weight, $\mathrm{kg}$

Air temperature for the livestock building, ${ }^{\circ} \mathrm{C}$

AER

Air exchange rate, $\mathrm{m}^{-1}$

$\mathrm{v}_{\mathrm{i}}, \mathrm{v}_{\mathrm{o}}$

Air velocities at the inlet and outlet, respectively, $\mathrm{m} \mathrm{s}^{-1}$

$\mathrm{A}_{\mathrm{i}}, \mathrm{A}_{\mathrm{o}}$

Inlet and outlet vent opening areas, respectively, $\mathrm{m}^{2}$

$\mathrm{V}$

Internal volume of the broiler house, $\mathrm{m}^{3}$.

$\mathrm{C}_{0}$

Initial concentration, mass fraction

$\mathrm{C}$

Gas concentration, mass fraction

$\mathrm{t}, \mathrm{t}_{0}$

$\mathrm{E}_{\mathrm{v}}$

Time, $\mathrm{s}$

The error between the predicted and measured values as a percentage to the initial data

$\mathrm{T}_{\text {cfd }}$

$\mathrm{T}_{\mathrm{i}}$

The predicted values from CFD simulation

$\mathrm{T}_{\mathrm{m}}$

The initial data

The measured values

\section{INTRODUCTION}

Tn South Korea, the number of chickens involved in commercial meat production was estimated in September 2010 to be 71 million

broilers (SSLI, 2010). The importance of environmental control for broiler houses to be within the optimum zone should be considered to increase the broilers productivity. The environmental factors including air temperature, air humidity, ventilation rate and contaminants concentrations are generally controlled by the airflow which depends on ventilation system design and operating (Seo et al., 2009). Maintaining an ideal internal air temperature in broiler zone during winter season reflects on broiler productivity.

Air temperature is an important factor in the growth, feed intake and body composition of broilers, (Howlider and Rose 1987). The internal air temperature has been recommended by Kennedy et al. (1991) to be ranged between $21 \sim 33^{\circ} \mathrm{C}$ according to the broiler age. The principles of the poultry house ventilation during winter are very different from those applied during summer (Donald 2003). Several researches have been done to reach the target air temperature by modifying the minimum ventilation systems. In South Korea where the experiment was done, the external air temperature could reach $-20{ }^{\circ} \mathrm{C}$ during winter season $(\boldsymbol{K M A}$ 2007). In order to create a suitable air temperature distribution in the 
broiler occupied zone, the building ventilation system must be designed and operated carefully. The essential components for designing the negative-ventilation system are the configuration of the inlet and the exhaust fan performance. These two components must be considered carefully to ensure that the air uniformly enters into the buildings at a low air velocity in broiler zone especially during the winter season. Broiler house is usually considered to be under minimum ventilation for moisture control and it also characterized by the necessity for supplemental heat to maintain the desired inside building temperature (Gates et al 1996).

A 3D-Computional Fluid Dynamics (CFD) simulation is a helpful technique to reach the ideal design by predicting with the thermal distribution inside the broiler house. This simulation can also provide information about the internal airflow rate within commercial livestock buildings (Blanes-Vidal et al., 2008; Lee et al., 2009; Seo et al., 2009). The accuracy of CFD modeling depends on many factors: time dependent versus steady state, $2 \mathrm{D}$ versus $3 \mathrm{D}$, discretization scheme, numerical algorithm, turbulence model, boundary conditions and proper simplification of complex geometry (Rong et al., 2010). Field experiments have some drawbacks which are reducing the measurements accuracy and produce unreal phenomenon. These drawbacks could be created because of unstable environmental conditions. CFD could also save the enormous cost, time, and effort of the field experiments to find out the optimum system (Lee et al., 2009). The models of heat, mass and momentum transfer, based on CFD are used to evaluate behavior of climate variables inside livestock structures where these CFD models are reducing the number of necessary experiments and improve the structures (Saraz et al., 2010).

This study aims to validate and use a CFD model to analyze the internal air temperature distribution in broiler zone in order to improve its uniformity and stability during winter season and accordingly enhancing the used ventilation system.

\section{MATERIAL AND METHODS}

\subsection{Description of experimental farm}

The field experiment aimed to validate the designed CFD model was conducted in 2010 using tunnel-ventilated broiler house. The examined 
farm is located at Nonsan city (Chungcheong Province), South Korea. This farm is accommodating with 6800 broilers in $378 \mathrm{~m} 2$ (9 m width X $42 \mathrm{~m}$ length). Throughout the broiler house, double winch curtains on each side were used to control the air temperature by rolling it up and down. The tunnel ventilation system adapted for summer weather using two fans (630 $\mathrm{mm}$ diameter) located in one side and three ventilated slots in the other side of the broiler house as shown in fig.1. These inlet slots are located at $1 \mathrm{~m}$ height from the floor with rectangular shape $(1.8 \mathrm{~m}$ width $\mathrm{X} 0.4 \mathrm{~m}$ height). Heaters are placed throughout the houses to maintain the recommended air temperature at productive levels. Chain feeding and tap watering stations supply the broilers with fodder and water but the manure removal is done manually. $20 \mathrm{~cm}$ litter of rice straw is distributed for the whole barn floor.

\subsection{Computational fluid dynamic technique}

There are three main procedures of CFD simulation should be followed: preprocessing, computation and post-processor.

Preprocessing was done using Gambit software (version 2.3, Lebanon, N.H. Fluent, Inc.) to design the computational domain. Mesh density could be considered as a critical point in domain design accordingly it has been conducted carefully into fine and dense meshes according to its position in the model. The second procedure is the main solver for numerical calculations which it has been done using a commercial Fluent software (version 6.2, Fluent, Inc., Lebanon, N.H., USA).
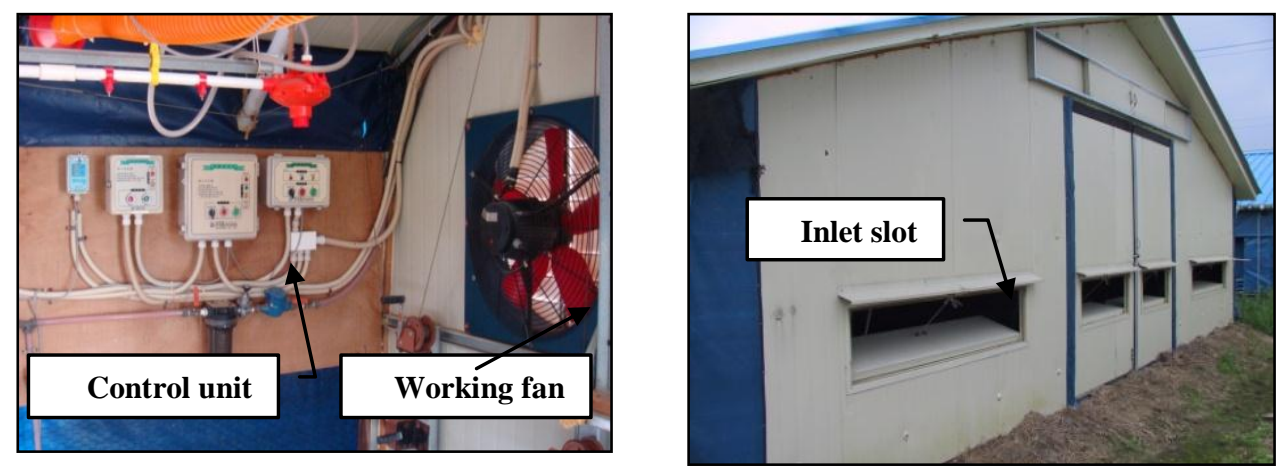

Figure (1): The examined tunnel-ventilated broiler house in Nonsan 
CFD technique is used to solve the Navier-Stocks and energy equations to predict the incompressible turbulent airflow and air thermal distribution in 3D broiler building. The non-isothermal model is characterized and described by the means of solving the nonlinear partial differential equations from the conversation of mass (Eq.1), momentum (Eq.2) and energy (Eq.3) equations (Lee and Short, 2000; Saraz et al., 2010).

$$
\begin{gathered}
\frac{\partial \rho}{\partial t}+\nabla(\rho \vec{v})=S_{m} \\
\frac{\partial}{\partial t}(\rho \vec{v})+\nabla(\rho \vec{v} \vec{v})=-\nabla P+\nabla(\bar{\tau})+\rho \vec{g}+\vec{F} \\
\frac{\partial}{\partial t}(\rho E)+\nabla(\vec{v}(\rho E+P))=\nabla\left(k_{e f f} \nabla T-\sum_{j} h_{j} \overrightarrow{J_{J}}+(\vec{\tau} \vec{v})\right)+S_{h}
\end{gathered}
$$

Renormalization-group (RNG) $\mathrm{k}-\varepsilon$ turbulent model is used in this computation as recommended by (Lee et al., 2007). The RNG k-E turbulence model was indicated using Eq. 4 and 5.

$$
\begin{aligned}
\rho \frac{d k}{d t} & =\frac{\partial}{\partial x_{i}}\left[\alpha_{k} \mu_{e f f} \frac{\partial k}{\partial x_{i}}\right]+G_{k}+G_{b}-\rho \varepsilon-Y_{m} \\
\rho \frac{d s}{d t} & =\frac{\partial}{\partial x_{i}}\left[\alpha_{s} \mu_{e f f} \frac{\partial s}{\partial x_{i}}\right]+C_{1 s} \frac{s}{k}\left(G_{k}+C_{3 \varepsilon} G_{b}\right)-C_{2 \varepsilon} \rho \frac{s^{2}}{k}-R
\end{aligned}
$$

RNG k- $\varepsilon$ turbulence model is using a mathematical technique to drive the equations of turbulence kinetic energy (k) Eq.6 and turbulence dissipation rate ( $\varepsilon$ ) Eq.7, (Fluent, 2006).

$$
\begin{aligned}
& k=\frac{1}{2}\left(u^{2}+v^{2}+w^{2}\right) \\
& \varepsilon=\frac{c_{\mu}^{\mathrm{g} / 4} \times k^{\mathrm{g} / x}}{l}, l=\min \left(k \times z_{n}, k \times \delta\right)
\end{aligned}
$$

The principle of this model is doing an iterative procedure to eliminate the smaller eddies and the replacement of their mean effect on the remaining larger eddies by increasing the viscosity.

The total heat production generated by birds was determined based on the assumption that the entire floor area was fully occupied with the broilers 
using Eq. 8 as proposed by Xin et al. (2001) which it correlated the heat generation with bird body weight.

$$
T H P=9.84 \times M^{0.75}\left(4 \times 10^{-5}(20-T)^{3}+1\right)
$$

\subsection{Experimental procedures}

The sequence working package in this study starts with measuring the environmental conditions using the field experiment. Second working package is to design a conventional CFD model for tunnel-ventilated broiler house. Form these two stages, the CFD validation for conventional case was done by analyzing the thermal condition. Final working package is designing a new model compatible for cold season and analyze the internal air distribution.

\subsubsection{Field experiment setup}

Thirty calibrated internal air temperature hygrometers (H8 hobo, Onset Inc., Pocasset, MA, USA) with 1 second intervals have been installed at broiler zone and $2 \mathrm{~m}$ height from the floor, as shown in Fig. 2. Meteorological data were collected at 15 second intervals using weather station (Campbell Scientific Inc., Lagon, Utah, USA). The Weather station has been installed above the main building roof after adjusting its direction using a compass. The air volume flow for the ventilators has been measured using an air flow traverse station (Flo-probes, Taehung, Korea).

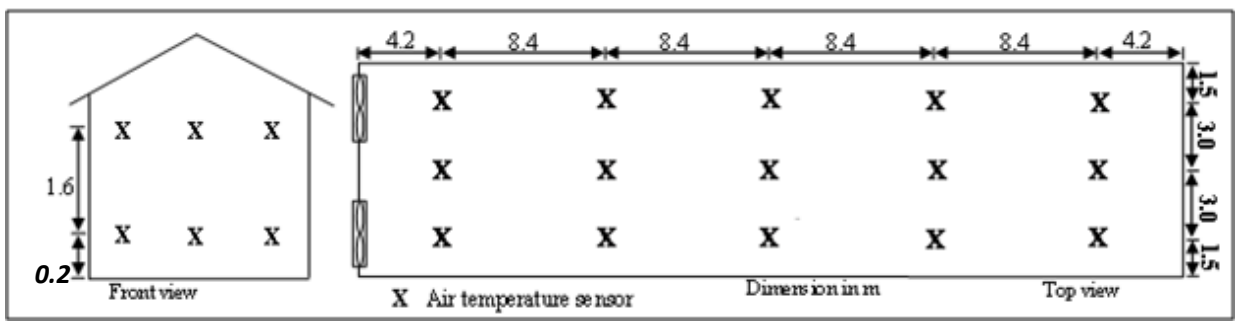

Figure (2): Sensor location inside the broiler house

\subsubsection{CFD models design}

In this study two 3D-CFD models have been created using Gambit. The first model is a conventional case for tunnel-ventilated broiler house which is used for validation as shown in Fig. 3a. The designed model 
with inlet pipes is the second model to be tested with cold weather. In the designed pipe-ventilated model, pipe inlets with $10 \mathrm{~cm}$ diameter parallel to the ceiling were used to supply the fresh air. These pipe inlets exist in 21 groups with $2 \mathrm{~m}$ distance spacing in each sidewall. Each group consists of two pipes, short pipe $(0.5 \mathrm{~m})$ and long pipe $(3 \mathrm{~m})$ to reach different places in the above area of the building and mix with warm and stagnant air there as shown in Fig. 3b.

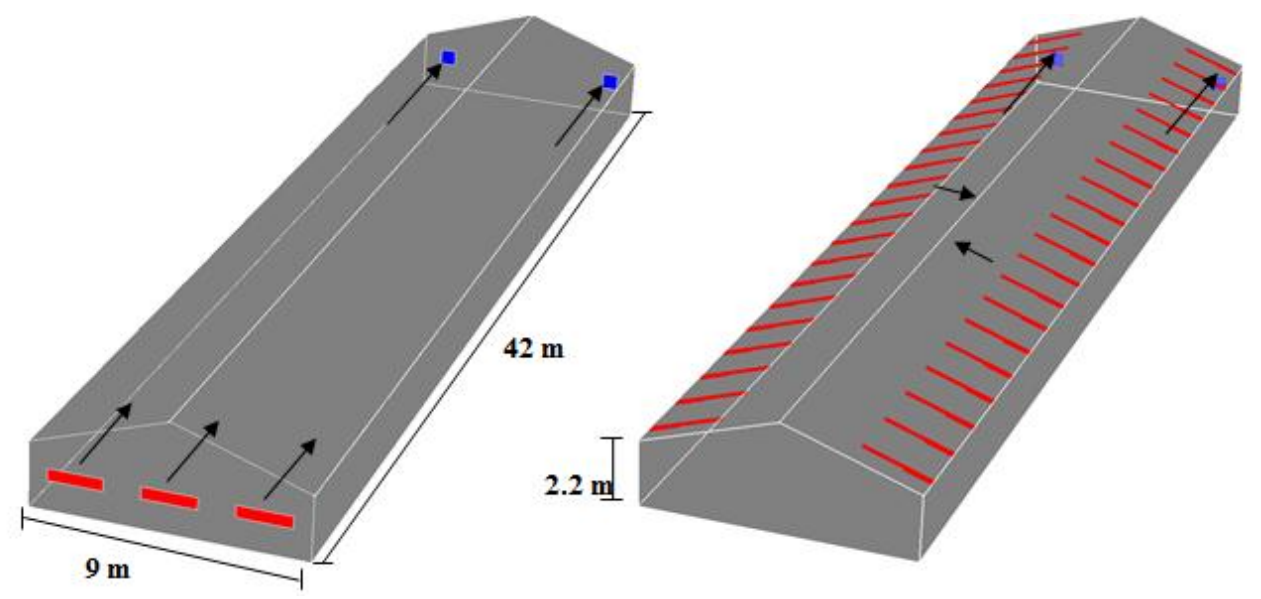

a) Conventional case

b) Pipe-ventilated case

Figure (3): Schematics of 3D-CFD models for two different ventilation systems used with broiler buildings

In winter season low ventilation rate generally should be used with broiler especially during the early age. The inlet-pipes are supposed to produce this low ventilation rate and achieve a uniform and stable distribution for internal air temperature in the occupied area with birds. The outlet air will be performed with two exhaust fans $(630 \mathrm{~mm}$ diameter) in the front wall of the building. The main data which is used in 3D-CFD models could be summarized in Table 1 while the various input values of boundary conditions for the simulation models are presented in Table 2.

The air ventilation rate has been computed using two different methods, conventional and tracer gas decay method (Hong et al., 2008; Seo et al., 
2009). According to the fan flow rate as $6000 \mathrm{~m}^{3} \mathrm{~h}^{-1}$, the designed ventilation rate is computed considering the volumetric flow rate using conventional method by Eq. 9:

$$
A E R=\frac{\Sigma v_{i} A_{i}}{V}=\frac{\Sigma v_{o} A_{o}}{V}
$$

The designed AER calculated using the Eq. 9 was $0.0896 \mathrm{~min}^{-1}$. To calculate the local ventilation rate using this method, limitations could be encountered such as the problems that accompany air circulation and stagnation effects. The tracer gas decay method (TGD) method has been used to overcome the previous problem in conventional method. The ventilation decreases the concentration of a tracer gas which was initially filled in the models uniformly. The reduction of gas concentration is recorded at different measuring operation points. Eq. 10 has been used to compute the overall and local ventilation rate.

$$
A E R=\frac{\ln \left(\frac{C_{0}}{C}\right)}{\left(t-t_{0}\right)} \times 60 \quad \min ^{-1}
$$

\begin{tabular}{|c|c|c|}
\hline \multirow{4}{*}{ Pre-processing } & Model size (m) & $\begin{array}{ll}\text { Length: } & 42 \\
\text { Width: } & 9 \\
\text { Ridge Height: } & 3.7 \\
\text { Eaves height: } & 2.2\end{array}$ \\
\hline & Mesh Type & Hexahedron, Pave, Tetra \\
\hline & Number of mesh & Around 2.7 million \\
\hline & skewnesses & 0.54 \\
\hline \multirow{3}{*}{ Main Module } & Turbulence model & RNG k- $\varepsilon$ turbulence model \\
\hline & Discretization & Second order upwind \\
\hline & Conditions & Unsteady state \\
\hline
\end{tabular}

Table (1): Data and variables used in the simulations 
Table (2): Constant input values for the case file of the CFD models

\begin{tabular}{|c|c|c|c|}
\hline \multicolumn{2}{|c|}{ Parameter } & Value & Unit \\
\hline \multirow{2}{*}{$\begin{array}{l}\text { Incoming } \\
\text { air temp. }\end{array}$} & Conventional & $0 \quad(273.18)$ & ${ }^{\circ} \mathrm{C}(\mathrm{K})$ \\
\hline & Designed case & $-5 \quad(268.18)$ & ${ }^{\circ} \mathrm{C}(\mathrm{K})$ \\
\hline \multirow{2}{*}{$\begin{array}{l}\text { Inside air } \\
\text { temp. }\end{array}$} & Conventional & $20(293.18)$ & ${ }^{\circ} \mathrm{C}(\mathrm{K})$ \\
\hline & Designed case & $25(298.18)$ & ${ }^{\circ} \mathrm{C}(\mathrm{K})$ \\
\hline \multicolumn{2}{|c|}{ Density of air } & 1.225 & $\mathrm{~kg} \mathrm{~m}^{-3}$ \\
\hline \multicolumn{2}{|c|}{ Viscosity of air } & $1.86 \mathrm{E}-05$ & $\mathrm{~kg} \mathrm{~m}^{-1} \mathrm{~s}^{-1}$ \\
\hline \multicolumn{2}{|c|}{ Thermal conductivity of air } & 0.02647 & $\mathrm{~W} \mathrm{~m} \mathrm{~K}^{-1}$ \\
\hline \multicolumn{2}{|c|}{ Specific heat of air } & 1006.43 & $\mathrm{~J} \mathrm{~kg}^{-1} \mathrm{~K}^{-1}$ \\
\hline \multicolumn{2}{|c|}{ Mass diffusivity of air } & $2.262 \mathrm{E}-05$ & $\mathrm{M}^{2} \mathrm{~s}^{-1}$ \\
\hline \multicolumn{2}{|c|}{ Molecular weight of air } & 28.966 & $\mathrm{~g} \mathrm{~mol}^{-1}$ \\
\hline \multicolumn{2}{|c|}{ air gravitational acceleration } & 9.81 & $\mathrm{~m} \mathrm{~s}^{-1}$ \\
\hline \multicolumn{2}{|c|}{ Atmospheric pressure } & 101.325 & $\mathrm{kPa}$ \\
\hline \multicolumn{2}{|c|}{ Outside $\mathrm{CO}_{2}$ concentration } & $0.00061(400)$ & Mas fraction (ppm) \\
\hline \multicolumn{2}{|c|}{ Inside $\mathrm{CO}_{2}$ concentration } & $0.003(2000)$ & Mas fraction (ppm) \\
\hline \multicolumn{2}{|c|}{ Generated NH3 concentration } & $2.065 \mathrm{E}-05(35)$ & Mas fraction (ppm) \\
\hline \multicolumn{2}{|c|}{ Designed ventilation rate } & 0.089 & Air exchanger $\min ^{-1}$ \\
\hline \multicolumn{2}{|c|}{ Bottom calculated heat flux } & 115 & $\mathrm{~W} \mathrm{~m}^{-2}$ \\
\hline
\end{tabular}

\subsection{CFD model validation}

The obtained data in terms of air temperature distribution in broiler zone from the designed CFD model has been verified to ensure the validation of CFD model with the real conditions. To achieve that, the comparison between the measured results from the field experiments and those obtained from CFD model were evaluated. This evaluation has been done by calculating (Eq. 11) the error between measured and simulated data as a percentage of the initial data $\left(\mathrm{E}_{\mathrm{v}}\right)$.

$$
E_{v}=\frac{T_{c f d}-T_{m}}{T_{i}}
$$




\section{RESULTS AND DISCUSSION}

From the model validation with the experimental data for air temperature distribution, the error between simulated and measured data $\left(\mathrm{E}_{\mathrm{v}}\right)$ has been estimated at different locations. The highest value was $0.46 \%$ which could be considered as an acceptable error. Accordingly, the designed model has been used to predict the thermal distribution of the air inside the broiler house using pipe-ventilation system.

\subsection{Ventilation rate and thermal air distribution inside the building}

To reach the target air temperature in broiler zone with good uniformity and stability was the main aim of the study. The pipe-ventilated system was used to ensure this uniformity and stability during the cold weather. As shown in Fig. 4, the turbulent airflow inside the building takes a spin in both halves of the building. The fresh air doesn't reach regularly to both longitude sides of the building, accordingly the air is keeping its stagnant statue in these areas. The average of air exchange rate (AER) for 600 second in broiler zone is $0.166 \mathrm{~min}^{-1}$. In comparison with designed ventilation rate $\left(0.089 \mathrm{~min}^{-1}\right)$, the pipe-ventilated system achieves $46 \%$ higher. As shown in Fig. 5, the ventilation rate is increasing rapidly at the beginning to reach its maximum at $2.19 \mathrm{~min}^{-1}$ after 20 second from running the simulation. Afterward the ventilation rate is also decreasing rapidly to $1.9 \mathrm{~min}^{-1}$ till 30 second and followed by stabilize rate.

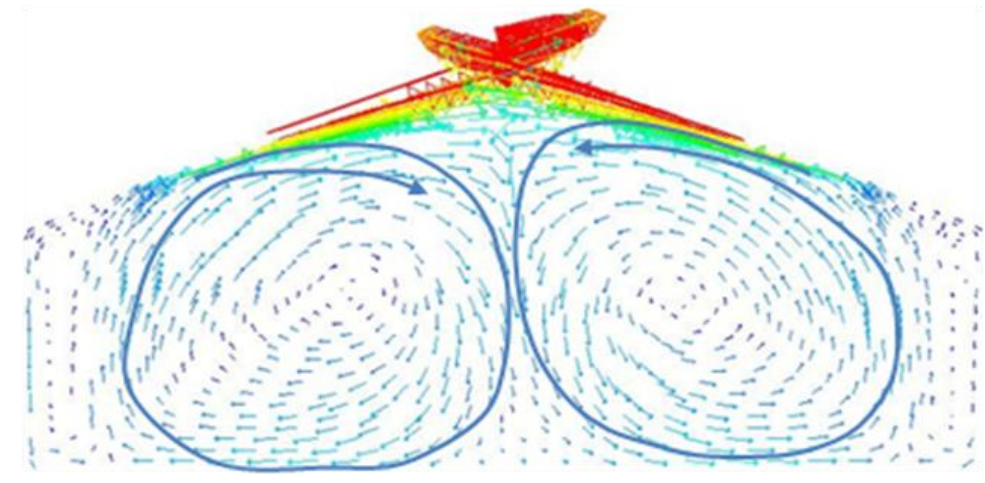

Air velocity $\left(\mathrm{ms}^{-1}\right)$
$3.00 \mathrm{e}+00$

$2.85 e+00$

$2.70 e+00$

$2.55 e+00$

$2.40 \mathrm{e}+00$

$2.25 e+00$

$2.10 e+00$

$1.95 e+00$

$1.80 \mathrm{e}+00$

$1.65 \mathrm{e}+00$

$1.50 \mathrm{e}+00$

$1.35 \mathrm{e}+00$

$1.20 \mathrm{e}+00$

$1.05 e \cdot 00$

$9.00 \mathrm{e}-01$

$7.50 \mathrm{e}-01$

$6.00 \mathrm{e}-01$

$4.50 e-01$

3.00e-01

$1.50 e-01$

$0.00 e+00$

Figure (4): The turbulent airflow inside the building 


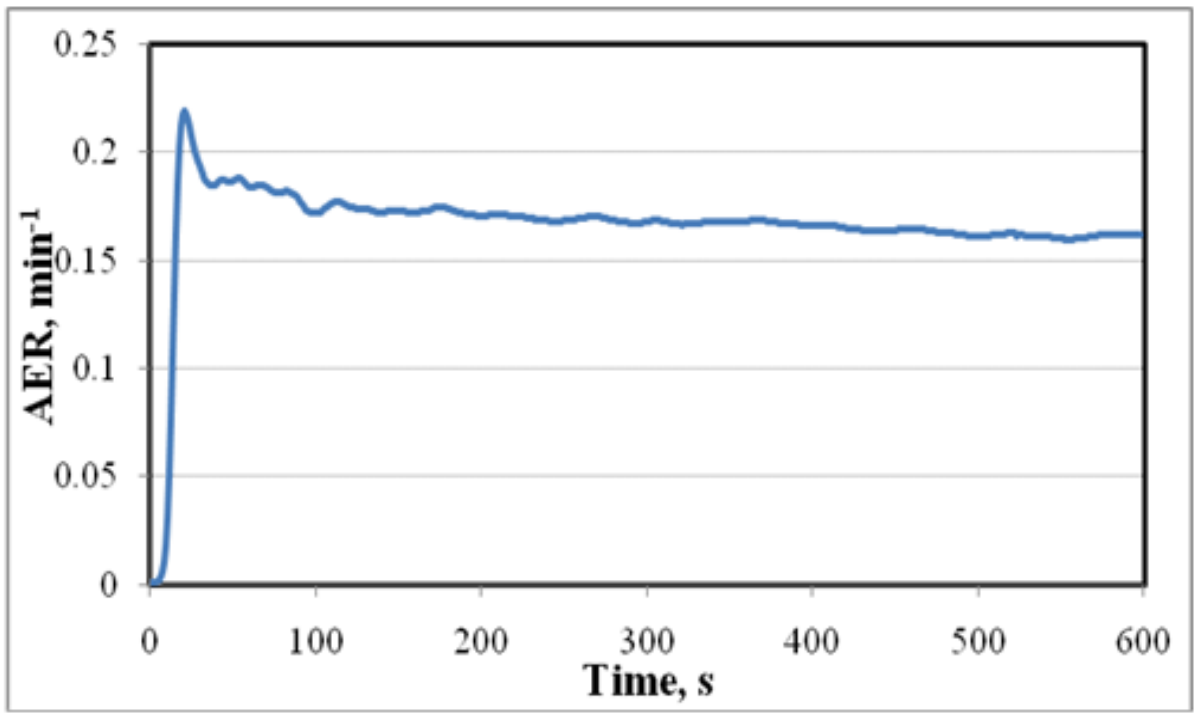

Figure (5): The ventilation rate in broiler zone for 600 second

Fig. 6 illustrates the thermal distribution for the internal air after 2, 10, 18 and 20 second from running the simulation. The fresh air at $-5{ }^{\circ} \mathrm{C}$ temperature is entering the building through the pipes-inlets under pressure. The cold air is descending regularly to reach the broiler zone and replaces the air in this region.

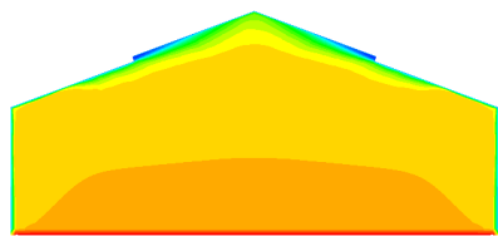

$2 \mathrm{~s}$

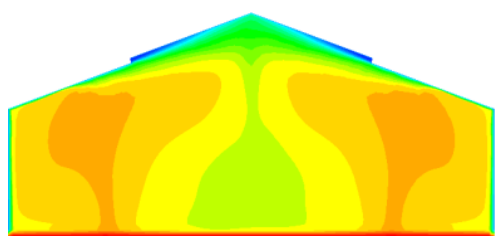

$18 \mathrm{~s}$

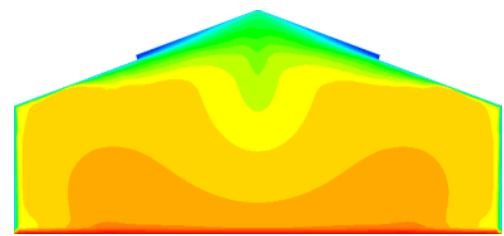

$10 \mathrm{~s}$

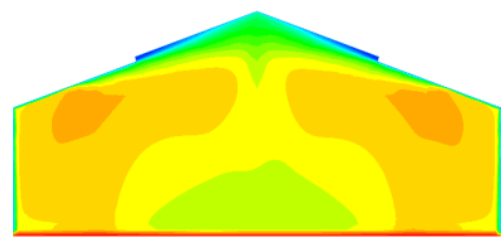

$20 \mathrm{~s}$

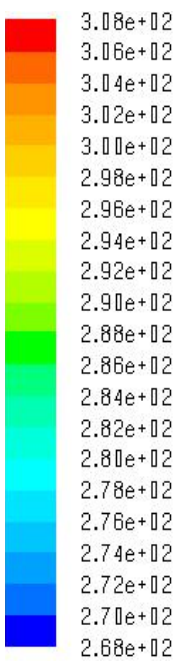

Temperature $(\mathrm{K})$

Figure (6): Thermal air distribution inside the broiler house 
The heat flux in the bottom is increasing the air temperature gradually in this zone and the warm air is ascending according to physical properties of air. The rate of increasing air temperature in this region by the effect of heat flux is higher than its decreasing by the effect of fresh air. After ten seconds, this phenomenon is disappearing and the air temperature will be decreased rapidly from 25.3 to $21.8{ }^{\circ} \mathrm{C}$ till 20 second. Afterward the air temperature is stabilizing in the broiler zone as shown in Fig. 7.

The fresh air at 2 seconds is occupying a place near to the ceiling. With running time, the air is descending gradually to the bottom and replacing with new supplements from the inlet-pipes as shown in Fig. 6 after 10 seconds. The air downward from the top takes its direction in the middle of the building lengthwise and then sat on the floor gradually. At 18 seconds the supplements of cold air to the floor will decrease and it will totally stop at 20 second. The warm air is ascending up and mixing with the cold air and reduce its temperature relatively. Fig. 6 indicated that after 20 seconds from running simulation time, the effect of ventilation could be negligible. Switching the ventilator off after this period would be helpful to save energy and maintain the air temperature.

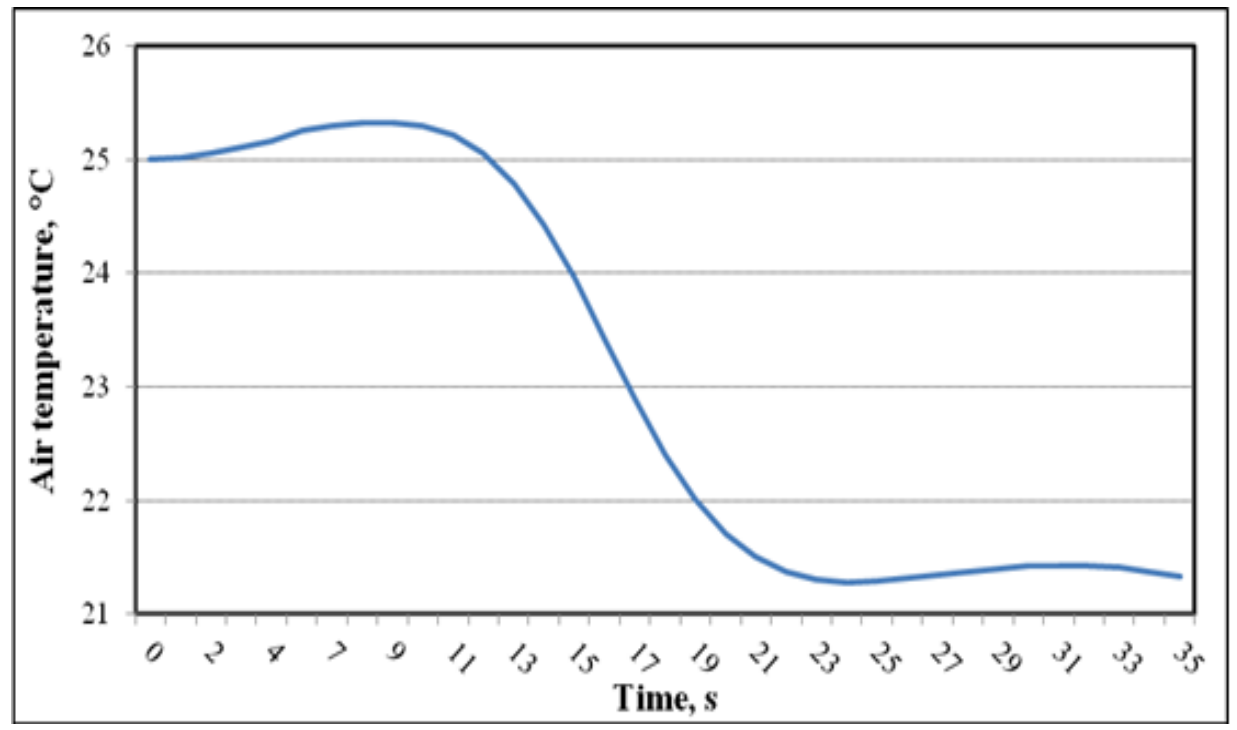

Figure (7): Conceptually air temperature distribution versus ventilation time in the broiler zone 
The thermal distribution in broiler zone could be described by Fig. 8 .
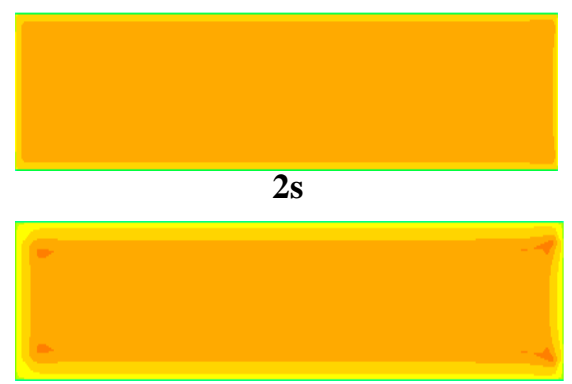

$10 \mathrm{~s}$

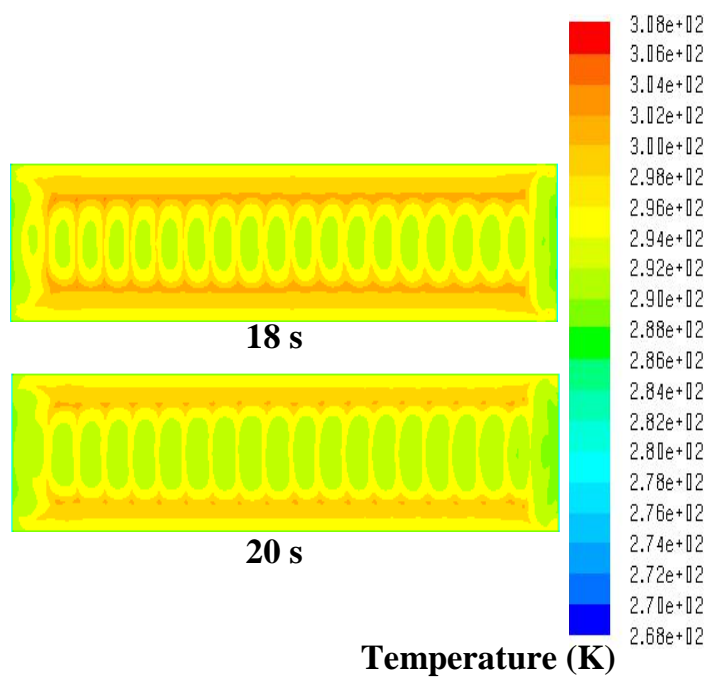

Temperature (K)

Figure (8): Air temperature distribution in the broiler zone

Slight difference in this distribution could be observed through the period from 2 to 10 seconds. This phenomenon is due to the non-arrival of cold air to this region. With running time till 18 seconds, low air temperature in broiler zone could be observed. The acceptable uniformity of the air temperature with maintaining a suitable distribution in broiler zone is clearly shows with 20 seconds. The high air temperature on both sides of the building dues to the lack of the arrival of cold air to these regions as described previously in Fig. 4.

\subsection{Ammonia concentration in broiler zone}

The essential target of this study is to predict the air temperature distribution in the broiler zone but also the ammonia concentration in this region must be taken into consideration. As shown in Fig.9, the concentration is almost stable at the first 10 seconds. Twenty-seconds following, the ammonia concentration is rapidly decreasing and subsequently the reduction is going regularly with running time. 


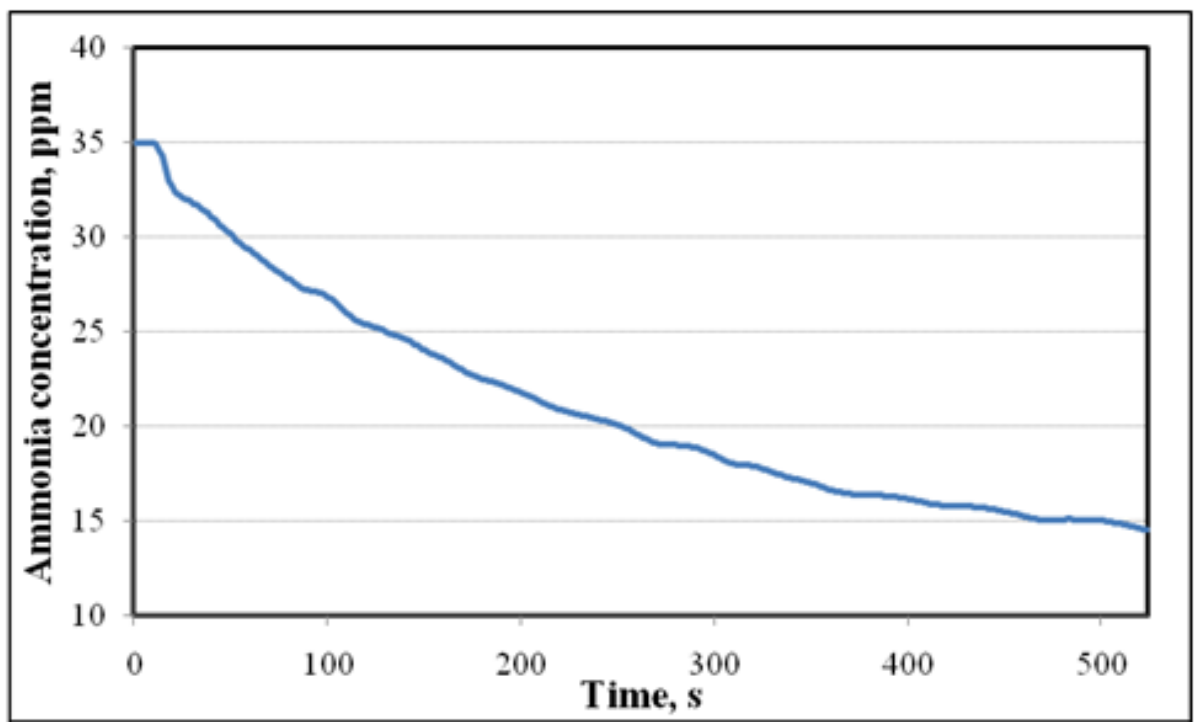

Figure (9): Ammonia Concentration versus ventilation time in the broiler zone

The reduction efficiencies of ammonia concentration in comparison with the initial concentration (35 ppm) are 0.2, 1.4, 3.6, 5.2, 6.6 and $8 \%$ after $10,20,30,40,50$ and 60 seconds from the running time, respectively.

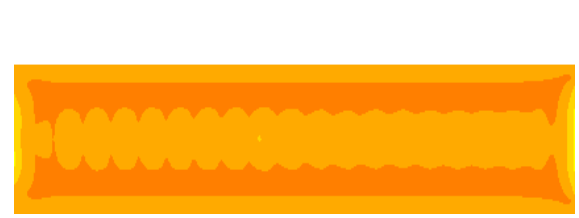

$10 \mathrm{~s}$

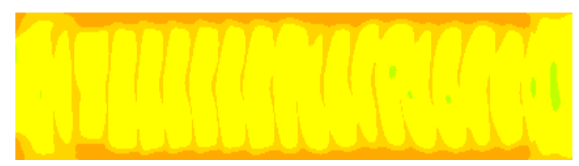

$30 \mathrm{~s}$

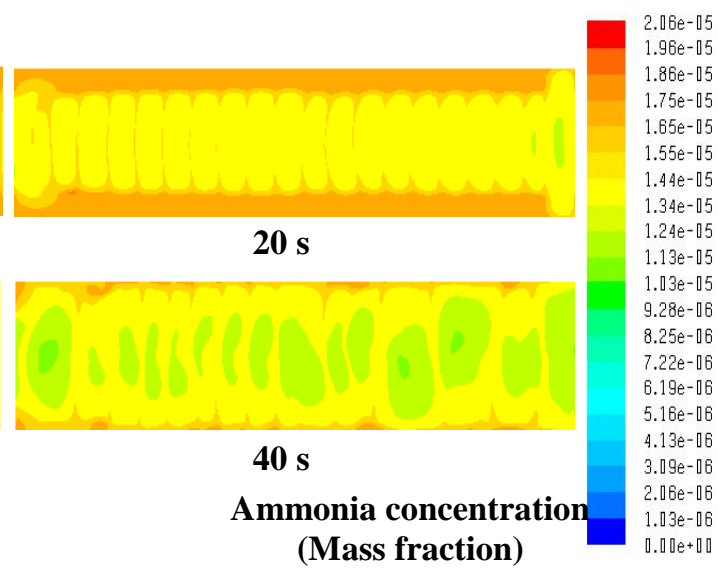

Figure (10): Ammonia concentration in the broiler zone

The ammonia concentration reduction after 10 seconds is negligible as shown in Fig. 10. The real change could be observed at 20 seconds where a low concentration is appeared in the middle of the building. High 
concentration is observed in both sides of the buildings due to the lack of air movement in this area. With running time, the reduction is appeared clearly where the fresh air is replacing the occupied air in this region.

\section{CONCLUSION}

This research have been done mainly to predict the air temperature distrbution in the broiler zone and eximine its uniformity. From the running simulation for the designed model after validation, the following results could be concluated:

1. The pipe-ventilated system is achieved a thermal uniformity in the broiler zone in the cold weather.

2. An acceptable uniformity of the air temperature distribution in broiler zone is clearly shows with 20 seconds.

3. After 20 seconds from running simulation time the effect of ventilation could be negligible and the ventilator could be switched off.

4. The average of air exchange rate (AER) for 600 second in broiler zone is $0.166 \mathrm{~min}^{-1}$.

5. The pipe-ventilated system succeeds to reduce the ammonia concentration in broiler zone. This reduction is directly associated with increasing the running time.

\section{REFERENCES}

Blanes-Vidal, V.; Guijarro, E.; Balasch, S.; and Torres, A.G. (2008): Application of computational fluid dynamics to the prediction of airflow in a mechanically ventilated commercial poultry building. Bio-systems Engineering, 100: 105-116.

Donald, J. (2003): Principles of successful wintertime broiler house ventilation. Avia tech. Volume (1). Number (4).

Fluent manual (2006): Fluent User Guide, Version 6.2.2. Lebanon,NH.

Gates, R. S.; Overhults, D. G.; and Zhang, S. H. (1996): Minimum ventilation for modern broiler facilities. American Society of Agricultural and Biological Engineers 39(3):1135-1144.

Hong, S -W.; Lee, I -B.; Hwang, H -S.; Seo, I -H.; Bitog, J.P.; Yoo, J-I.; Kim, K-S.; Lee, S-H.; Kim, K-W. and Yoon, $\mathrm{N}-\mathrm{K}$. (2008): Numerical simulation of ventilation efficiencies of 
naturally ventilated multi-span greenhouses in Korea. American Society of Agricultural and Biological Engineers 51(4): 1417-1432.

Howlider, M.A.R.; and Rose, S.P. (1987): Temperature and the growth of broilers. World's poultry science journal. 43: 228-237.

Kennedy, D. A.; Leonard, J. J.; and Feddes, J. J. (1991): Field test of a PVC plate heat exchanger for animal housing. American Societyof Agricultural Engineers, Applied Engineering in Agriculture. Vol. 7(4): 457-460.

KMA, Korea Meteorological Administration. (2007): Annual Meteorological Data. http://web.kma.go.kr/eng. Accessed 5 June 2011.

Lee, I -B.; Sase, S.; and Sung, S -H. (2007): Evaluation of CFD accuracy for the ventilation study of a naturally ventilated broiler house. Japan Agricultural Research Quarterly 41(1): 53-64.

Lee, I. B.; Sase, S.; Han, H.; Hong, H.; Sung, S.; Hwang, H.; Hong, S.; Seo, I.; and Kwon, S. (2009): Ventilation design for a chick incubator using computational fluid dynamics. JARQ 43 (3): 227-237.

Lee, I-B.; and Short, T.H. (2000): Two-dimensional numerical simulation of natural ventilation in a multi-span greenhouse. American Society of Agricultural and Biological Engineers, 43(3): 745-753.

Rong, L.; Elhadidi, B.; Khalifa, H.E.; and Nielsen, P.V. (2010): CFD Modeling of Airflow in a Livestock Building. The $7^{\text {th }}$ international conference on indoor air quality, ventilation and energy conservation in buildings. Syracuse, USA

Saraz, J.A.O.; Damasceno, F.A.; Gates, R.S.; Rocha, K.S.O.; Tinôco, I.F.; and Marin, O.L.Z. (2010): 3D-CFD Modeling of a Typical Uninsulated and Internal Misting Tunnel Ventilated Brazilian Poultry House. ASABE Annual International Meeting. David L. Lawrence Convention CenterPittsburgh, Pennsylvania. 
Seo, I-H.; Lee, I-B.; Moon, O-K.; Kim, H-T.; Hwang, H-S.; Hong, S W.; Bitog, J.P.; Yoo, J-I.; Kwon, K-S.; Kim, Y-H.; and Han, J-W. (2009): Improvement of the ventilation system of a naturally ventilated broiler house in the cold season using computational simulations. Bio-systems Engineering 104 (1): 106-117.

SSLI, Statistical Survey of Livestock Industry (2010): NAPQMS (National Agricultural Product Quality Management Service), South Korea.

Xin, H.; Berry, I.L.; Tabler, G.T.; and Costello, T.A. (2001): Heat and moisture production of poultry and their housing systems: broilers. Transactions of the ASAE 44(6): 1851-1857.

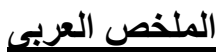

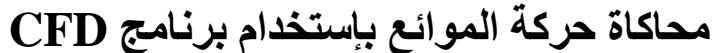

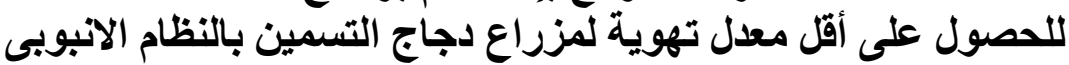

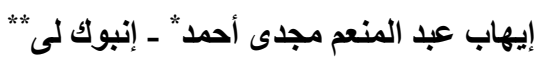

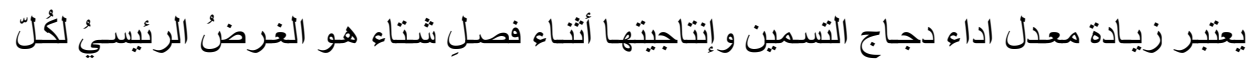

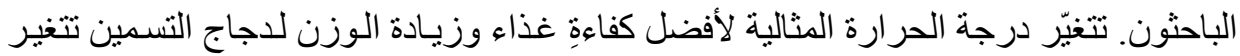

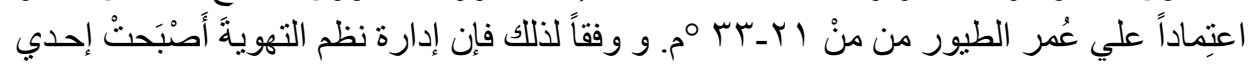

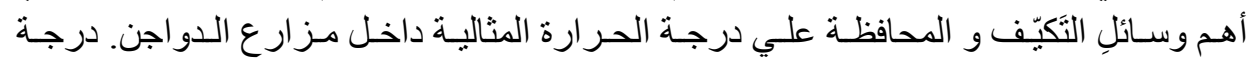

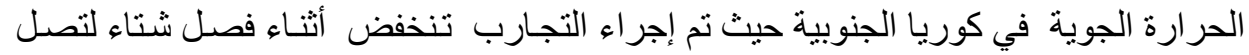

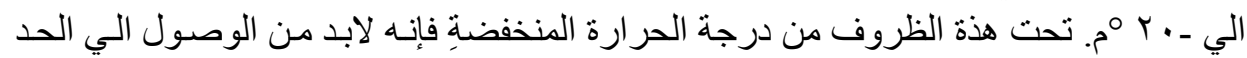

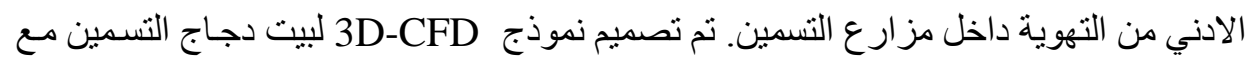

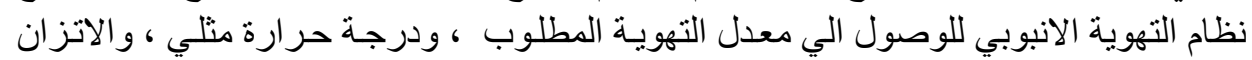

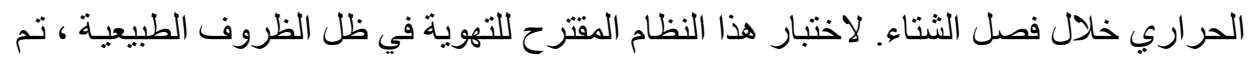

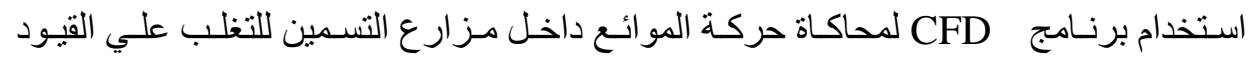

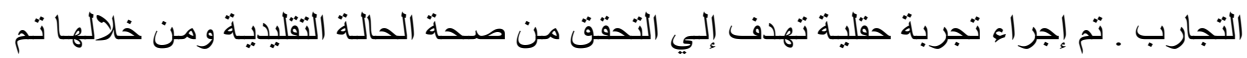

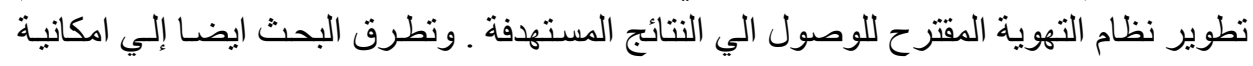

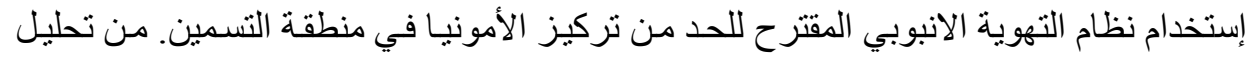

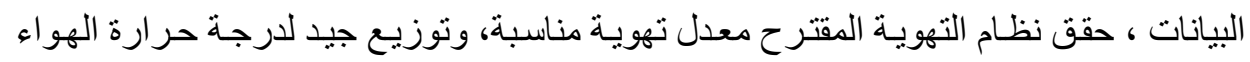
الداخلية و كذلك الحد من تركيز الامونيا.

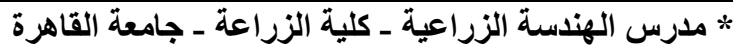
** استاذ الهندسة الزراعية المساعد ـ كلية الزراعة الزراعة وامعة علوم الحياة - جامعة سئول الوطنية ـ كوريا الجنوبية 